\title{
Interference from the presence of other substances in detecting and determining barbiturates in biological material
}

\author{
S. L. TOMPSETT \\ From the Department of Clinical Chemistry (University of Edinburgh), Royal Infirmary, Edinburgh
}

SYNOPSIS Investigations of the interference by other substances in the detection and determination of barbiturates in biological materials are described.

The detection and determination of barbiturates in biological material is now almost universally carried out by ultraviolet spectrophotometry, utilizing the differences in absorbance at $p \mathrm{H} 13 / 10$ or $p \mathrm{H} \mathrm{10/2}$, or a combination of both (Wright and Johns, 1953; Broughton, 1956; Curry, 1961). Occasionally the results of this method are affected by interference from the presence of other substances (Curry, 1961), and this paper is concerned with investigations into certain aspects of this problem but not with any proposed new method or modifications in existing methods for the detection and determination of barbiturates in biological material.

The initial or preparative approach to the examination of biological material for the presence of barbiturates has shown great variation which may be related to variability in the composition of the materials employed. Chloroform and ether have been the solvents of choice. I prefer to use chloroform since it is a much more selective solvent and interference is less likely to be encountered. If one is interested in barbiturate metabolites, then the aqueous phase must be saturated with ammonium sulphate and ether used as the solvent (Moss and Jackson, 1964; Moss, 1965; Tompsett, 1965). Circumstances will, however, dictate whether it is required to identify the presence of barbiturates. I have employed this extraction procedure in examining urine after the suspected ingestion of drinamyl and amphetamine has already been detected.

Extraction may be carried out from aqueous solutions with an acid or a neutral reaction. The former has shown some variation since, in some cases, acidity has been achieved by the addition of a mineral acid, $e g$, hydrochloric acid, whilst in others, phosphate buffers, eg, of $p \mathrm{H} 6$, have been used. Received for publication 26 August 1968.
Extracts obtained from aqueous solutions with an acid reaction may contain strongly acidic substances, eg, salicylic acid, which can interfere in the final ultraviolet spectrophotometric examination. Such interfering substances can be removed by washing the chloroform extracts with an aqueous phosphate buffer solution $(p \mathrm{H} 7 \cdot 0)$ or a similar aqueous solution, $e g$, an aqueous solution of sodium hydrogen carbonate adjusted to $p \mathrm{H} 7.0$ by the addition of hydrochloric acid and used without delay. Whole blood must be extracted with chloroform at a neutral reaction. If extraction with chloroform is carried out after the addition of mineral acid, haematin will be present in the final extracts and can cause considerable interference. No interference is encountered if serum or plasma is acidified by the addition of hydrochloric acid before chloroform extraction. When extractions are carried out from a medium with a 'neutral' reaction, such should be ensured by the addition of a suitable buffer. Actually whole blood, as received in the laboratory, possesses a faintly alkaline reaction.

Many basic drugs are extractable by chloroform from aqueous solutions with a neutral reaction. It is preferable to dehydrate chloroform extracts before further use by adding anhydrous sodium sulphate. Traces of interfering material are thereby eliminated. The chloroform extracts may be evaporated to dryness and the residue dissolved in $0.45 \mathrm{~N}$ sodium hydroxide or the barbiturate extracted from chloroform solution by shaking with aqueous $0.45 \mathrm{~N}$ sodium hydroxide. The latter method is preferable since much interfering material, eg, basic drugs, glutethimide, and methaqualone are eliminated.

The present investigations have been based on the assumptions that (1) extractions are carried out with chloroform at an acid or a neutral reaction and (2) 
barbiturate is extracted from chloroform solution with aqueous $0.45 \mathrm{~N}$ sodium hydroxide before ultraviolet spectrophotometry. Drugs likely to interfere with barbiturate detection and determination would thus be weak acids or ampholytes, possessing the above physical properties and showing absorbance within the ultraviolet region of the spectrum. Investigations have been generally confined to this type of substance.

\section{EXPERIMENTAL}

ULTRAVIOLET SPECTRA The presence or absence of a particular substance in an extract was assessed by ultraviolet spectrophotometry, an appropriate blank being employed, on a recording spectrophotometer (Unicam SP 800). Recordings were made over the range 200 to 350 millimicrons. In the absence of a recording instrument, readings should be made at intervals of 10 millimicrons. As soon as readings are made they should be applied to graph paper, so that this interval may be enlarged or reduced as appropriate.

Ultraviolet recordings were made of all the substances under examination for reference purposes in the presence of $\mathbf{N}$ hydrochloric acid and $\mathbf{N}$ sodium hydroxide. The range of concentrations employed depended upon the nature of the substance under investigation and this had to be determined by experiment.

The ultraviolet spectra of phenylbutazone, sulphathiazole, acetyl p-aminophenol, dicoumarin, p-cresol, theophylline, and phenytoin in acid ( $\mathrm{N}$ hydrochloric acid) and alkali ( $\mathbf{N}$ sodium hydroxide) are shown in Figure 1;

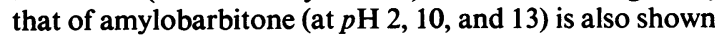
in Figure 1.

EXTRACTION BY CHLOROFORM This property was examined at acid, neutral, and alkaline reactions by the following procedure:

Quantities (three samples), each of $1 \mathrm{mg}$, of the substance under examination and contained in $10 \mathrm{ml}$ of water were placed in each of three $50 \mathrm{ml}$ glass-stoppered measuring cylinders. These, in order, were treated as follows: for the acid reaction, $1 \mathrm{ml}$ of $10 \mathrm{~N}$ hydrochloric acid was added; and for the neutral reaction, $1 \mathrm{ml}$ of $10 \mathrm{~N}$ hydrochloric acid was added, followed by solid sodium hydrogen carbonate until approximate neutrality had been attained $(p \mathrm{H} \mathrm{7.0)}$. This may be assessed when gas $\left(\mathrm{CO}_{2}\right)$, ceases to be formed, when further sodium hydrogen carbonate is added, and by the use of indicator test papers. For the alkaline reaction $1 \mathrm{ml}$ of $10 \mathrm{~N}$ sodium hydroxide was added, then $40 \mathrm{ml}$ of chloroform was added to each cylinder and the contents shaken vigorously for two minutes. After separation, the aqueous phase was separated and rejected. Anhydrous sodium sulphate was added to effect dehydration. The chloroform extract was filtered and $30 \mathrm{ml}$ of the filtrate evaporated to dryness in an all-glass vacuum still. The residue waa dissolved in $10 \mathrm{ml}$ of $\mathrm{N}$ hydrochloric acid or $\mathrm{N}$ sodium hydroxide, depending upon the ultraviolet absorbance properties of the substance. Ultraviolet recordings were made against an appropriate blank. In some cases, it was necessary to effect greater dilution in order to obtain the whole of the ultraviolet spectrum on the chart.

Results for the three reactions are shown in Table I.

EXTRACTION BY N SODIUM HYDROXIDE AND N HYDROCHLORIC ACID FROM CHLOROFORM SOLUTION This investigation was carried out with those substances (Table I) that could be extracted by chloroform from aqueous solutions with an acid or neutral reaction.

The substance (originally $1 \mathrm{mg}$ ) contained in $30 \mathrm{ml}$ of

\section{TABLE I}

RESULTS OF EXTRACTION BY CHLOROFORM

Substance

Reaction of Aqueous Phase

Acid Neutral Alkaline

Sulphonamides

Sulphaguanidine

Phthalylsulphathiazole

Succinylsulphathiazole

Sulphacetamide

Sulphamethizole

Sulphafurazole

Sulphaphenazole

Sulphasomizole

Sulphamethoxydiazine

Sulthiamine

Sulphasomidine

Sulphamethoxypyridazine

Sulphamezathine

Sulphanilamide

Sulphapyridine

Sulphamerazine

Sulphathiazole

Sulphadimethoxine

Sulphadiazine

Hydrazine Derivatives

Nialamide

Isocarboxazide

Iproniazid

Coumarins

Dicoumarin

Warfarin

4-Hydroxycoumarin

7-Hydroxycoumarin

Indanediones

Phenindione

Xanthine Derivatives

Caffeine

Theobromine

Theophylline

Monohydroxyphenols

Phenol

$o$ - and $p$-Cresol

Thymol

Chloroxylenol

Guaiacol

Miscellaneous

Barbiturates

$N$-Acetyl $p$-aminophenol

Phenylbutazone

Oxyphenbutazone

Phenytoin

Morphine

p-Aminophenol

Phenylacetylurea

Vanillic acid diethylamide

Glutethimide

Methaqualone

Bemegride

$+=$ extracted $;-=$ not extracted. 

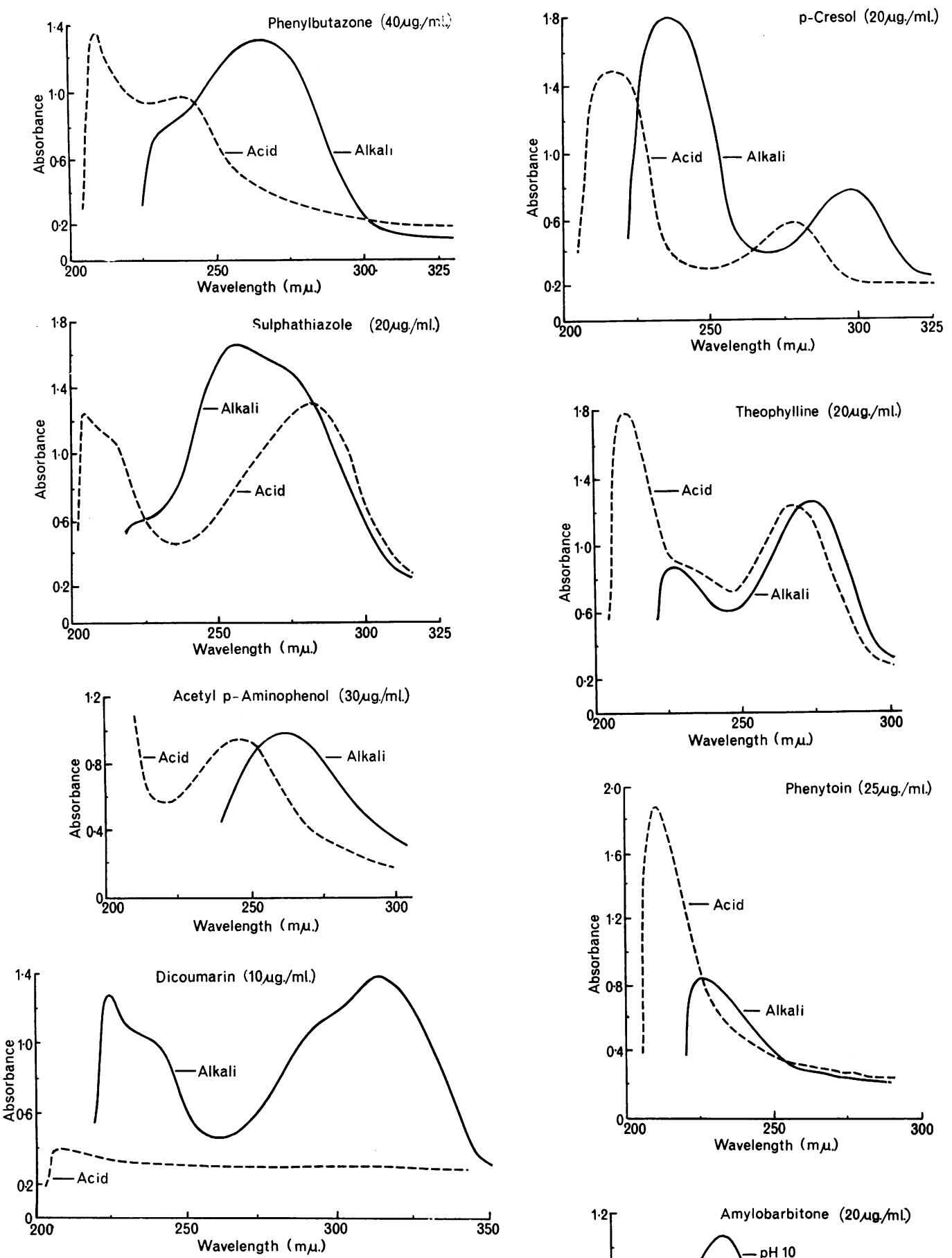

FIG. 1. The ultraviolet spectra of certain substances, namely, phenylbutazone, sulphathiazole, acetyl p-aminophenol, dicoumarin, p-cresol, theophylline, and phenytoin, that can produce interference in the detection and determination of barbiturates by ultraviolet spectrophotometry. The spectra were recorded in $N$ sodium hydroxide and $N$ hydrochloric acid.

The ultraviolet spectrum of amylobarbitone, recorded at $\mathrm{pH} 2,10$, and 13, is also shown.

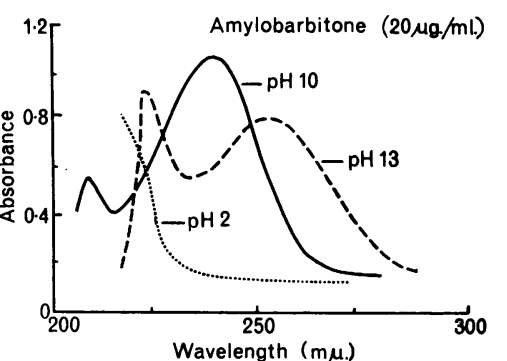


chloroform was prepared as described above, by extraction at neutral reaction. This was shaken vigorously for two minutes with either $10 \mathrm{ml}$ of $\mathrm{N}$ sodium hydroxide or $10 \mathrm{ml}$ of hydrochloric acid. The aqueous extracts were separated and examined by ultraviolet spectrophotometry, appropriate blanks being used. Results are shown in Table II.

\section{TABLE II}

EXTRACTION OF CHLOROFORM SOLUTIONS BY AQUEOUS N HYDROCHLORIC ACID AND N SODIUM HYDROXIDE

\begin{tabular}{lll} 
Substance & $\begin{array}{l}\text { N Hydrochloric } \\
\text { Acid }\end{array}$ & $\begin{array}{l}\text { N Sodium } \\
\text { Hydroxide }\end{array}$ \\
\hline Barbiturates & - & + \\
Phenytoin & - & + \\
Warfarin & - & + \\
7-Hydroxycoumarin & + & + \\
4-Hydroxycoumarin & + & + \\
Sulphapyridine & + & + \\
Sulphadiazine & + & + \\
Sulphamethoxydiazine & + & + \\
Sulthiamine & + (trace) & + \\
Dicoumarin & - & + \\
Phenylbutazone & - & + \\
Oxyphenbutazone & + & + \\
Acetyl p-aminophenol & + & + \\
Morphine & + & + \\
Theobromine & + & - \\
Theophylline & - & - \\
Caffeine & - & + \\
Methaqualone & - & - \\
Glutethimide & + & + \\
Iproniazid & - & (turns \\
Phenylacetylurea & + & + \\
$p$-Aminofhenol & & + \\
Bemegride & - & \\
Monohydroxyphenols & - & \\
'extracted by 5N hydrochloric acid. &
\end{tabular}

\section{RESULTS AND DISCUSSION}

A large number of substances behave in a similar fashion to the barbiturates. It is preferable to discuss these in groups.

SULPHONAMIDES It will be noted that only a certain number are extractable by chloroform and thus can cause interference. Sulphonamides generally show distinct individual differences in the shape of ultraviolet spectra, and this may assist in individual identification. In contrast to the barbiturates, the sulphonamides may be removed from chloroform solution by aqueous solutions of mineral acids. With the exception of the antiepileptic drug, sulthiamine, sulphonamides may be recognized by the application of the Bratton and Marshall reaction (1939).

PHENBUTAZONE AND OXYPHENBUTAZONE Oxyphenbutazone is a metabolite of phenbutazone but is also used as a drug on its own account. These two substances behave in a similar fashion to the barbiturates. Phenbutazone, as distinct from the barbiturates and oxyphenbutazone, is extractable 2 है
from aqueous solutions by heptane.

These two substances, by treatment with hot 2 hydrochloric acid, are converted into diazotisable? substances which are recognizable by the application of the Bratton and Marshall reaction (Moss, 1954 Tompsett, 1968).

THEOPHYLLINE, THEOBROMINE, AND CAFFEINE Thes饮 substances possess almost identical ultraviolet spectra. Caffeine should produce no interference;but interference can be expected from the presence ot theophylline and theobromine. Theophylline is constituent of a number of pharmaceutical prepare ations used in the treatment of certain respiratorito disorders.

PHENOLS The monohydroxyphenols-phenol, $o=$ and $p$-cresol, guaiacol, and thymol-possess almosi identical ultraviolet spectra. Since phenols circulateand are excreted almost entirely in conjugated forms it is fortunate that little interference from these substances is experienced. Wright (1954) notedo interference from phenol present as a contaminanto in heparin.

N-ACETYL p-AMINOPHENOL This substance can arise in blood and urine as the result of the ingestion of the substance itself (paracetamol) or phenacetin (Brodie and Axelrod, 1948, 1949). Usually it is present in conjugated forms and hence no inter $\overrightarrow{\overline{0}}$ ference is experienced. Following very high dosages, the unconjugated substance may be encountered in both blood and urine. Following ingestion, blood. levels fall very rapidly, hence interference may beㅇ encountered more frequently in examinations of urines than of blood.

The presence of this substance in extracts can be readily confirmed (Tompsett, 1968).

COUMARINS AND PHENINDIONES Many of the sub? stances of this group are used in anticoagulant therapy, and show individual and distinctive differences in ultraviolet spectra. So far I hav@ experienced no interference from the presence of these substances in 'barbiturate' extracts.

PHENYTOIN This antiepileptic drug may be encountered together with barbiturate. Its presence may be confirmed by the use of the method of Wallace (1968)

BEMEGRIDE, GLUTETHIMIDE, AND METHAQUALONE The presence of bemegride can result in distortion of the ultraviolet spectra. This problem has been discussecक्ष by Broughton (1956).

Methaqualone does not interfere but is present in 
the chloroform extract after the barbiturate has been removed by extraction with aqueous $0.45 \mathrm{~N}$ sodium hydroxide. The presence of this substance can be readily verified by evaporating the chloroform extract to dryness and dissolving the residue in ethanol. The ethanol solution is examined by ultraviolet spectrophotometry, an appropriate blank being employed.

Glutethimide does not interfere but is present in the chloroform extract after removing barbiturate by extraction with aqueous $0.45 \mathrm{~N}$ sodium hydroxide. The presence of this substance can be readily confirmed. The chloroform extract is evaporated to dryness and the residue examined by ultraviolet spectrophotometry using the procedure of Goldbaum, Williams, and Koppanyi (1960).

The following suggestions may be useful: examine by ultraviolet spectrophotometry 'barbiturate' ex-

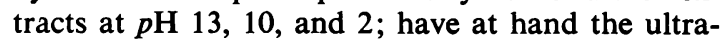
violet spectra of all possible interfering substances (range 200-350 $\mathrm{m} \mu$ ).

It will be apparent that the procedure for barbiturate detection and determination has a use in screening for the presence of other drugs.

\section{REFERENCES}

Bratton, A. C., and Marshall, E. K., Jr. (1939). J. biol. Chem., 128, 537. Brodie, B. B., and Axelrod, J. (1948). J. Pharmacol., 94, 22.

$\longrightarrow,-$, (1949). Ibid., 97, 58.
Broughton, P. M. G. (1956). Biochem., J., 63, 207.

Curry, A. S. (1961). In Toxicology: Mechanisms and Analytical Methods, edited by C. P. Stewart and A. Stolman, vol. 2, p. 153. Academic Press, New York and London.

Goldbaum, L. R., Williams, M. A., and Koppanyi, T. (1960). Analyt. Chem., 32, 81 .

Moss, D. G. (1954). J. clin. Path., 7, 344.

Moss, M. S. (1965). Proc. Ass. clin. Biochem., 3, 218.

Moss, R. A., and Jackson, J. V. (1964). In 3rd International Meeting in Forensic Immunology, Medicine, Pathology and Toxicology, April 16-24, 1963, London (Excerpta Med. int. Congr. Ser., 80), p. 104. Excerpta Med., Amsterdam.

Tompsett, S. L. (1965). Proc. Ass. clin. Biochem., 3, 286.

- (1968). J. clin. Path., 21, 366.

Wright, J. T. (1954). J. forens. Med., 1, 175.

- , and Johns, R. G. S. (1953). J. clin. Path., 6, 78.

Wallace, J. E. (1968). Analyt. Chem., 40, 978.

\section{ADDENDUM}

Since this paper was written, interference in the detection and determination of barbiturates by ultraviolet spectrophotometry from the presence of 4-hydroxyantipyrine, a metabolite of antipyrine, has been found. This substance is excreted in the free and in conjugated forms but only the former produces interference. The extraction properties of 4hydroxyantipyrine are similar to those of the barbiturates. The ultraviolet spectra of 4-hydroxyantipyrine at $p \mathrm{H} 13$ and 10 are almost identical with a peak at 235 millimicrons. At $p \mathrm{H} 2$ there is considerably less absorption at this wavelength. Antipyrine, as a complex with chloral, is a major constituent of the preparation marketed as Welldorm. 